\title{
PROJETO DE UM SISTEMA DE TRATAMENTO DE ESGOTO PARA CANTEIRO DE OBRAS: UM ESTUDO DE CASO
}

\author{
Marcelo de Jesus Rodrigues da Nóbrega \\ Pós-Doutor em Engenharia Civil (UERJ) \\ Professor da UNIGAMA, CEFET-RJ e Universidade Santa Úrsula. \\ engmarcelocefet@terra.com.br
}

Fabiano Battemarco da Silva Martins

Mestrado Acadêmico em Engenharia Agrícola e Ambiental pela Universidade Federal Rural do Rio de Janeiro, RJ, BRASIL Graduado em Engenharia Civil, UNISUAM, Rio de Janeiro, RJ, Brasil

fabianobattemarco@gmail.com

Guilherme Mathias Vargas

Graduado em Engenharia Civil, UNISUAM, Rio de Janeiro, RJ, Brasil

Guilherme.mvargas@hotmail.com

\begin{abstract}
Resumo
O estudo apresentado tem o objetivo avaliar o sistema de esgotamento sanitário do canteiro de obras objeto deste estudo de caso, utilizado como canteiro de apoio as obras de duplicação da BR493/RJ - Acesso ao Porto de Itaguaí, com período de utilização de 18 meses. Foi realizado revisão da literatura técnica e da legislação ambiental, verificando se as condições exigíveis em diretrizes e normas foram atendidas quando da elaboração do projeto de implantação do canteiro. $O$ estudo apresentará o dispositivo Fossa Séptica executado quando da implantação do canteiro de obras e será levantado através dos relatórios mensais de supervisão a população contribuinte mês a mês afim de projetar um sistema de esgotamento sanitário de maior eficiência adequando a demanda da obra, garantindo a qualidade do efluente. O canteiro de obras será detalhadamente apresentado, bem como suas dependências e ocupação, determinante para o melhor dimensionamento do sistema de esgotamento sanitário e um novo sistema projetado afim de que atender toda a legislação ambiental vigente.
\end{abstract}

Palavras-chave: Canteiro de Obras, Dimensionamento, Fossa Séptica, Esgotamento Sanitário.

DESIGN OF A SEWAGE TREATMENT SYSTEM FOR A CONSTRUCTION SITE: A CASE STUDY

\begin{abstract}
The study presented is to evaluate the sewage system construction site subject of this case study, used as a support site the duplication works of the BR-493 / RJ - Access to the Port of Itaguai, with 18 usage period months. It was conducted review of technical literature and of environmental legislation, making sure that the conditions required in guidelines and standards have been met when preparing the site of the deployment project. The study will present the Septic Fossa device performed when the implementation of the construction site and will be raised through the supervision monthly reports the taxpayer population every month in order to design a sewage system for greater efficiency adjusting the work demand, ensuring quality the effluent. The construction site will be presented in detail as well as their dependencies and occupation,
\end{abstract}


determinant for the best design of the sewage system and a new system designed in order that meet all environmental regulations.

Keywords: Construction Site, Dimensioning, Septic Tank, Sewerage.

\section{INTRODUÇÃO}

A legislação ambiental está a cada dia buscando a proteção e punição para atividades lesivas ao meio ambiente. $\mathrm{Na}$ atualidade leis, diretrizes e normas são utilizados para fixar condições de modo que o meio ambiente seja respeitado.

Órgãos como o Instituto Brasileiro de Meio Ambiente e dos Recursos Naturais Renováveis IBAMA, executor do Sistema Nacional de Meio Ambiente (SISNAMA), a quem compete licenciar ambientalmente as atividades e obras com significativo impacto ambiental, de âmbito nacional ou regional, podendo ser desenvolvidas em parcerias com os estados e municípios.

O canteiro de obra do caso em estudo obteve o licenciamento junto ao IBAMA através da Licença de Instalação (LI) № 926/2013, válida por quatro anos, para obtenção do mesmo foi elaborado e apresentado o projeto executivo do canteiro bem como o dimensionamento do sistema de esgotamento sanitário.

O projeto, construção e operação de sistemas de tratamento de esgoto sanitário, incluindo tratamento e disposição de efluentes tem por objetivo preservar a saúde, a higiene, o conforto e a segurança dos habitantes de áreas servidas.

A verificação do sistema de tratamento de esgoto para um canteiro de obra, prédimensionado a partir de estimativas de ocupação e prazo de obra, será detalhadamente descrita

Serão verificados se o sistema de tratamento construído quando da implantação do canteiro, atendeu o que preconiza as diretrizes e normas as necessidades para o período estabelecido de contrato uma vez que a ocupação do mesmo e consequentemente a contribuição de despejos variaram de acordo com as fases da obra, bem como apontadas as possíveis penalidades.

Sendo assim, objetivou-se com este estudo, através da Revisão da Literatura e da Legislação Ambiental que estabeleceram os critérios e obrigações a serem cumpridas para implantação do sistema de tratamento de esgotamento sanitário do canteiro de obras em estudo.

\section{DESENVOLVIMENTO}


A maior parte da água tratada utilizada para atender as necessidades humanas retorna na forma de esgoto. Após o uso da água em seu estado potável, há uma alteração nas características químicas da água tornando-a esgoto. O esgoto é uma mistura de água e matéria orgânica (fezes, urina e água do serviço doméstico), onde $99 \%$ do volume de esgoto pode ser água e aproximadamente $1 \%$, pode ser de matéria orgânica e o objetivo principal do tratamento de esgoto é desfazer essa mistura.

Segundo Azevedo Neto (2015), cidades onde o sistema de abastecimento de água atende maior número de pessoas e apresentam o sistema de esgoto ainda carente, as águas servidas acabam poluindo o solo, contaminando águas superficiais e freáticas e frequentemente passam a escoar pelas valas e sarjetas, constituindo perigosos focos de disseminação de doenças.

A coleta e transporte desses despejos é realizada através de condutos, que recebem as contribuições e encaminham para as Estações de Tratamento de Esgoto (ETE).

Na Figura 1 é apresentado uma representação gráfica dos elementos de uma rede convencional de coleta de esgoto sanitário.

Figura 1 - Sistema de coleta convencional de esgoto

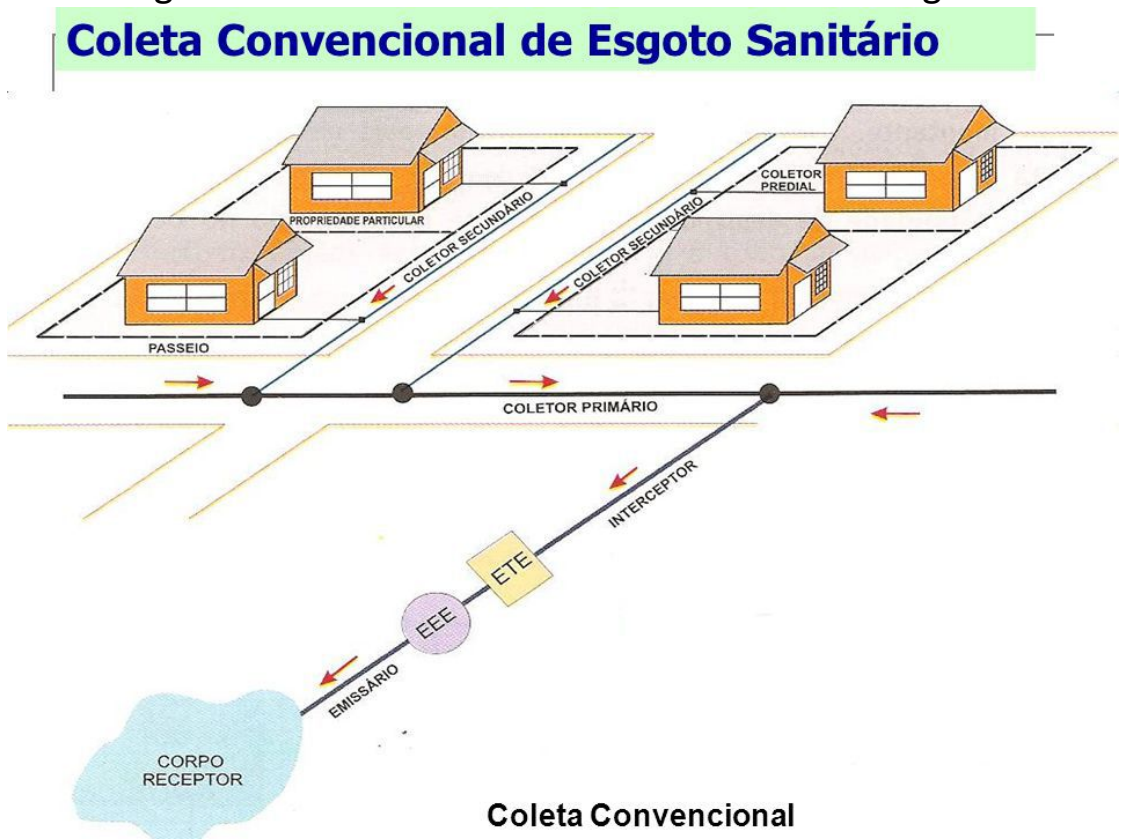

Fonte: Neto (2015)

As ETE's são responsáveis pela remoção de poluentes lançados ao corpo receptor. Segundo Nuvolari (2011) quando um composto orgânico é lançado num corpo receptor, dá-se início ao processo natural de degradação denominado autodepuração, englobando mecanismos como 
dispersão, diluição, sedimentação, dentre outros. As fases do tratamento do esgoto por uma ETE são demonstradas na Figura 2.

Figura 2 - Estação de Tratamento de Esgoto Urbano

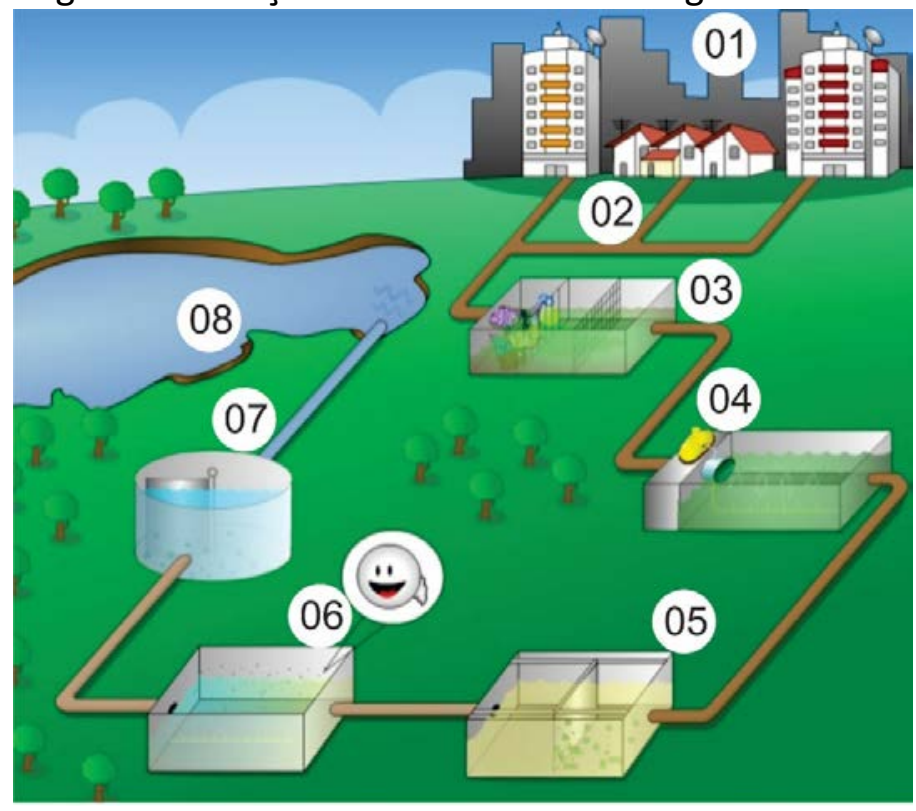

Fonte: Nuvolari (2011)

Legenda da imagem:

- 1 - Cidade;

- 2 - Rede de esgotos;

- 3-Grades;

- 4-Caixa de areia;

- 5 - Decantador primário;

- 6 - Fossas de aeração;

- 7-Decantador secundário e

- 8 -Rio.

A Demanda Bioquímica de Oxigênio (DBO) é a quantidade de oxigênio necessária para estabilizar a matéria orgânica. Quanto menor o nível de DBO, menos poluente é o efluente, conhecido o grau de poluição de esgoto pode-se definir qual dispositivo de tratamento melhor se adéqua (NBR 13.969/1997).

2.2 Tratamentos de Esgoto.

Tendo como objetivo a remoção de poluentes e matéria orgânica, sólidos em suspensão, bem como os organismos patogênicos e nutrientes, o tratamento de esgoto pode ser classificado nos seguintes níveis: preliminar, primário, primário avançado, secundário (ou convencional) e terciário (ou avançado). 
A classificação é dada de acordo com os métodos aplicados ao tratamento do esgoto, podendo haver combinações de operações físicas, processos químicos e processos biológicos, que podem ser classificados da seguinte forma segundo Bernardes e Soares (2004): operações físicas métodos de tratamento em que a aplicação de força física predomina. Ex. Gradeamento, mistura e sedimentação; processos químicos - métodos de tratamento em que a remoção de contaminantes ocorre pela adição de produtos químicos. Ex. Precipitação química, adsorção e desinfecção e processos biológicos - métodos de tratamento em que a remoção de poluentes ocorre por meio de atividade biológica. São utilizados para remoção de matéria orgânica e de nutrientes e são derivados dos processos aeróbios e anaeróbios.

Há dois tipos de sistema de coleta de esgoto, sistema individual ou sistema coletivo, o sistema individual são soluções implantadas na maioria das vezes em áreas rurais, podendo ser utilizadas também em áreas não dotadas de sistemas públicos e coletivos, e o sistema coletivo são dimensionados para uma área de médio ou grande adensamento populacional, exigindo uma rede coletora de esgoto podendo esta ser classificada em sistema unitário e sistema separador absoluto.

O sistema coletivo consiste em coletar e transportar o esgoto sanitário e águas pluviais de uma comunidade para uma Estação de Tratamento de Esgoto (ETE) ou ao efluente final, podendo ser os seguintes tipos de sistemas coletivos (Bernardes \& Soares, 2004): sistema unitário ou Combinado - a rede é construída para coletar esgoto, águas de chuvas e águas de infiltração dentro da mesma canalização até o seu destino final; sistema Misto ou Separador Parcial - são conduzidas águas residuárias e águas de infiltração para uma canalização de coleta e transporte de esgoto, reduzindo a contribuição de águas pluviais e separador Absoluto - os esgotos sanitários e as águas pluviais percorrem em tubulações próprias e independentes.

Além disso, tem-se o sistema individual que também são chamados de descentralizados, segundo Pacheco e Volschan (2009), os sistemas individuais são soluções usadas quando da inexistência de rede coletora de esgoto pública.

Há diferentes tipos de dispositivos para tratamento individual de esgoto sanitário, como fossa séptica, lodos ativados, lagoa de estabilização entre outras, mas como se trata de um estudo de caso onde a solução adotada foi o sistema fossa séptica e filtro anaeróbio, apresentaremos somente especificações dos mesmos. 


\subsubsection{Fossa séptica}

O dispositivo de esgotamento mais utilizado no sistema individual é o Fossa Séptica, unidade para tratamento de esgotos por processos de sedimentação, flotação e digestão, a Norma NBR 7229/93 - Projeto, Construção e Operação de Sistemas de Tanques Sépticos fixa as condições exigíveis para projeto, construção e operação de sistemas de tanques sépticos, incluindo tratamento e disposição de efluentes e lodo sedimentado e tem por objetivo preservar a saúde pública e ambiental, a higiene, o conforto e a segurança dos habitantes de áreas servidas por estes sistemas.

A Figura 3 apresenta um esquema com os principais componentes de um tanque séptico.

Figura 3 - Esquema Funcional do Tanque Séptico

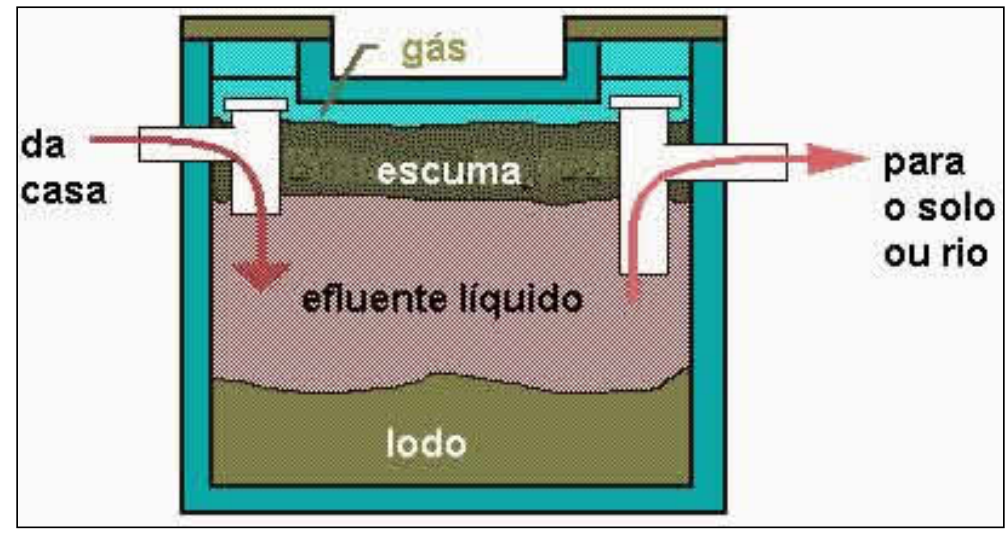

Fonte: NBR 7229/93

A utilização do sistema de tanque séptico está restrita ao tratamento de esgoto doméstico e, em casos onde não haver rede de coleta de esgotamento sanitário por uma rede pública, ao esgoto sanitário. A norma NBR 7229/93 descreve detalhadamente as restrições ao uso do sistema, bem como as condições específicas para implantação do mesmo.

Para dimensionamento do Tanque Séptico, segundo a norma NBR 7229/93, o volume útil do tanque séptico de ser calculado pela fórmula (Equação 1):

$V=1000+N(C \times T+K \times L f)$ Equação (1)

Onde:

$V=$ volume útil, em litro

$N$ = número de pessoas ou unidades de contribuição

$C=$ contribuição de despejos, em litros/pessoa $\mathrm{x}$ dia ou em litros/unidade $\mathrm{x}$ dia (Tabela 1 )

$T=$ período de detenção, em dias (Tabela 2) 
$K=$ taxa de acumulação de lodo digerido em dias, equivalente ao tempo de acumulação de lodo fresco (Tabela 3)

$L f=$ Contribuição de lodo fresco, em litro/pessoa $\times$ dia ou em litro/unidade $\mathbf{x}$ dia (Tabela 1 )

Tabela 1 - Contribuição diária de esgoto (C) e de lodo fresco (Lf) por tipo de prédio e de ocupante

\begin{tabular}{|c|c|c|c|}
\hline \multirow{2}{*}{\begin{tabular}{l}
\multicolumn{1}{c}{ Prédio } \\
1. Ocupantes permanentes \\
- Residência \\
Padrão alto \\
Padrão médio \\
Padrão baixo \\
- Hotel (exceto lavanderia e cozinha) \\
- Alojamento provisório
\end{tabular}} & \multirow{2}{*}{$\begin{array}{l}\text { Unidade } \\
\text { Pessoa } \\
\text { Pessoa } \\
\text { Pessoa } \\
\text { Pessoa } \\
\text { Pessoa }\end{array}$} & \multicolumn{2}{|c|}{ Contribuição (C) e Lodo Fresco (Lf) } \\
\hline & & $\begin{array}{c} \\
160 \\
130 \\
100 \\
100 \\
80\end{array}$ & $\begin{array}{l}1 \\
1 \\
1 \\
1 \\
1\end{array}$ \\
\hline $\begin{array}{l}\text { 2. Ocupantes temporários } \\
\text { - Fábrica em geral } \\
\text { - Escritório } \\
\text { - Edifícios públicos ou comerciais } \\
\text { - Escolas (externatos) e locais de } \\
\text { longa permanência } \\
\text { - Bares } \\
\text { - Restaurantes e similares } \\
\text { - Cinemas, teatros e locais de curta } \\
\text { permanência } \\
\text { - Sanitários públicos * }\end{array}$ & $\begin{array}{c}\text { Pessoa } \\
\text { Pessoa } \\
\text { Pessoa } \\
\\
\text { Pessoa } \\
\text { Pessoa } \\
\text { Refeição } \\
\text { Lugar } \\
\text { Bacia sanitária }\end{array}$ & $\begin{array}{l}70 \\
50 \\
50\end{array}$ & $\begin{array}{l}0,20 \\
0,10 \\
0,10\end{array}$ \\
\hline
\end{tabular}

Fonte: ABNT NBR 7229/93

Tabela 2 - Período de detenção dos despejos, por faixa de contribuição diária

\begin{tabular}{|c|c|c|}
\hline \multirow{2}{*}{ Contribuição Diária (L) } & \multicolumn{2}{|c|}{ Tempo de Detenção } \\
\cline { 2 - 3 } & Dias & Horas \\
\hline Até 1500 & 1,00 & 24 \\
De 1501 a 3000 & 0,92 & 22 \\
De 3001 a 4500 & 0,83 & 20 \\
De 4501 a 6000 & 0,75 & 18 \\
De 6001 a 7500 & 0,67 & 16 \\
De 7501 a 9000 & 0,58 & 14 \\
Mais que 9000 & 0,50 & 12 \\
\hline
\end{tabular}

Fonte: ABNT NBR 7229/93

Tabela 3 - Taxa de acumulação total de lodo (K), em dias, por intervalo entre limpezas e temperatura do mês mais frio

\begin{tabular}{|c|c|c|c|}
\hline $\begin{array}{c}\text { Intervalo Entre Limpezas } \\
\text { (anos) }\end{array}$ & \multicolumn{2}{|c|}{ Valores de K por Faixa de Temperatura Ambiente (t), em ${ }^{\circ} \mathbf{C}$} \\
\cline { 2 - 4 } & $\mathbf{t} \leq \mathbf{1 0}$ & $\mathbf{1 0} \leq \mathbf{t} \leq \mathbf{2 0}$ & $\mathbf{t} \mathbf{2 0}$ \\
\hline 1 & 94 & 65 & 97 \\
3 & 134 & 105 & 137 \\
4 & 174 & 145 & 177 \\
5 & 214 & 185 & 217 \\
\hline
\end{tabular}

Fonte: ABNT NBR 7229/93 
Os tanques sépticos podem ser cilíndricos ou retangulares, empregados em situações de maior e menor profundidade, respectivamente. As medidas internas do tanque apresentam valores mínimos preconizados na NBR 7229/93, profundidade útil com valores mínimos e máximos recomendados (Tabela 4), diâmetro interno mínimo de 1,10 m, largura interna mínima de 0,80 m e relação comprimento/largura (para tanques retangulares) mínima de 2:1 e máxima de 4:1.

Tabela 4 - Profundidade útil mínima e máxima, por faixa de volume útil

\begin{tabular}{|c|c|c|}
\hline Volume Útil $\left(\mathbf{m}^{\mathbf{3}}\right)$ & Profundidade Útil Mínima (m) & Profundidade Útil Máxima (m) \\
\hline Até 6,0 & 1,20 & 2,20 \\
De 6,0 a 10,0 & 1,50 & 2,50 \\
Mais que 10,0 & 1,80 & 2,80 \\
\hline
\end{tabular}

Fonte: ABNT NBR 7229/93

\subsection{Metodologia}

Através do objetivo do presente estudo que tem como finalidade avaliar as atividades desenvolvidas pelo canteiro estudado, com a finalidade de identificar as não conformidades de algumas legislações que estabeleceram os critérios e obrigações a serem cumpridas para implantação do sistema de tratamento de esgotamento sanitário do canteiro de obras em estudo, além de preservar o patrimônio da empresa.

O meio de investigação escolhido para tal artigo foi de caráter bibliográfico, que se baseia em estudos já realizados ao estudar artigos, trabalhos de conclusão de cursos, leis, entre outros, esse meio investigativo juntamente com os métodos escolhidos foi de total importância para uma melhor compreensão do caso abordado no presente artigo.

Por meio de uma abordagem qualitativa, tornou-se possível enxergar e interpretar as informações que foram reveladas por meio dos dados nas respectivas tabelas.

A presente pesquisa foi classificada como exploratória. De acordo com Gil (2008, p. 41), “o objetivo da pesquisa exploratória é proporcionar maior familiaridade com o problema, com vistas a torná-lo mais explícito ou a constituir hipóteses, que deem sustentação ao objetivo central do estudo". Referindo-se aos resultados, pode-se classificar como aplicada, já que o resultado encontrado pode contribuir para mudanças na realidade existente com a utilização de práticas normativas pela empresa estudada. 


\subsection{Estudo de Caso}

O canteiro de obras objeto de estudo, ficou localizado na rua 46 - Lotes 99 ao 103 - Quadra 46, bairro Brisa Mar, Itaguaí - RJ, km 122,5 da BR-493, conforme mapa de localização apresentado na Figura 4.

Figura 4 - Mapa de localização do canteiro

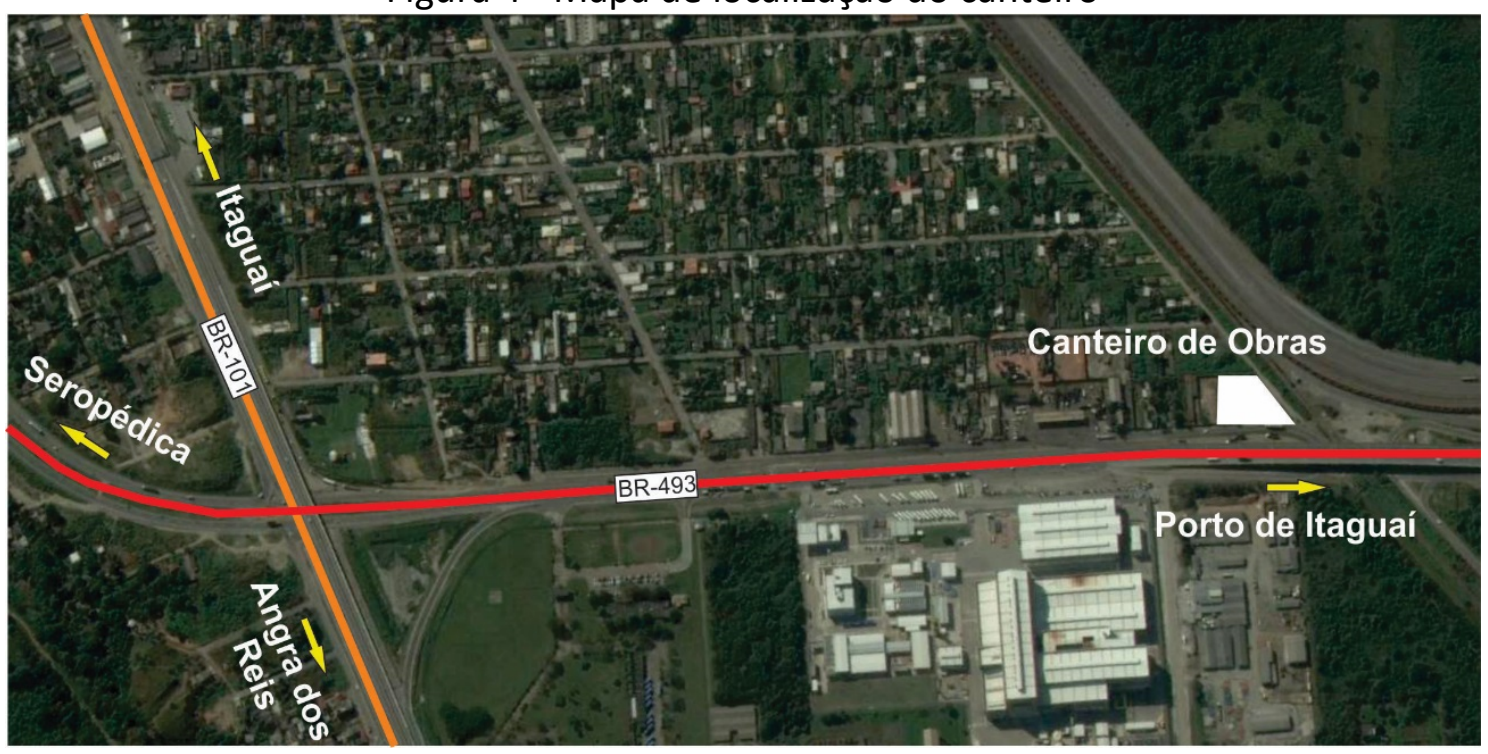

Fonte: Google Eath (2020)

Contendo $3.642 \mathrm{~m}^{2}$ de terreno, onde $947 \mathrm{~m}^{2}$ de área ocupada sendo dividida em $203 \mathrm{~m}^{2}$ de vestiário, $383 \mathrm{~m}^{2}$ de escritório e almoxarifado, $259 \mathrm{~m}^{2}$ de refeitório e cozinha e $102 \mathrm{~m}^{2}$ de laboratório, para melhor visualização do layout do canteiro, está sendo apresentado em anexo (Anexo I), planta do canteiro de obras em formato A3.

O canteiro estudado teve sua montagem iniciada em dezembro de 2012 e início de operação em janeiro de 2013, o vestiário foi projetado para atender 340 trabalhadores e devidamente aparamentado conforme determina a NR-18 - Condições e Meio Ambiente de Trabalho na Indústria da Construção. Tratando de uma obra rodoviária com extensão de 3,5 km, foram utilizados nas frentes de trabalho banheiros químicos.

O sistema de coleta sanitária do canteiro foi construído de forma a atender todos os banheiros em funcionamento nos setores do canteiro, bem como ao vestiário e refeitório, todo esgoto foi coletado por uma rede de tubos interligados e conduzidos por gravidade para o sistema de tratamento de efluentes. 
A concepção do projeto de tratamento do esgotamento sanitário produzido no canteiro foi baseada nos seguintes parâmetros: tratamento adequado do esgoto gerado; sistema de fácil implantação; preservação do meio ambiente e atendimento à legislação vigente.

Em função desses parâmetros e baseados nas normas da ABNT - NBR 7229/93 e NBR 13969/97 e na DZ-215.R-4 - Diretriz de controle de carga orgânica biodegradável em efluentes líquidos de origem não industrial - FEEMA, foi adotado solucionar o tratamento dos esgotos utilizando-se um sistema que trate os efluentes deste empreendimento, de forma simples e com baixo custo de implantação e manutenção. Buscou-se produzir um efluente que estivesse dentro dos padrões estabelecidos pelos órgãos ambientais.

Para estudos dos padrões de emissão dos efluentes líquidos, foram consideradas as Resoluções dos Órgãos a nível estadual e federal que regulamentam o assunto. Os despejos após o tratamento não devem apresentar valores acima dos máximos estabelecidos no capítulo IV da Resolução $n^{\circ}$ 357/2005 do Conselho Nacional do Meio Ambiente (CONAMA) e a eficiência do tratamento deve respeitar também as exigências complementares definidas na DZ-215.R-4 apresentada no quadro 3.1-1, devidamente representado na Tabela 5.

Tabela 5 - Eficiência de remoção para dimensionamento da unidade de tratamento de esgotos sanitários de atividades industriais, estabelecimentos comerciais e canteiro de obras - atividades não residenciais com cozinha.

\begin{tabular}{|c|c|c|c|}
\hline $\begin{array}{c}\text { Carga Orgânica Bruta } \\
\text { Total (c) (Kg DBO/dia) }\end{array}$ & $\begin{array}{c}\text { Número de } \\
\text { Funcionários }\end{array}$ & $\begin{array}{c}\text { Eficiência Mínima } \\
\text { de Remoção de } \\
\text { DBO (\%) }\end{array}$ & $\begin{array}{c}\text { Exemplo de tipo de } \\
\text { tecnologia }\end{array}$ \\
\hline $\mathrm{C} \leq 5$ & Até 100 & 30 & Fossa séptica \\
\hline $5<\mathrm{C} \leq \mathbf{2 5}$ & De 101 a 500 & 65 & $\begin{array}{c}\text { Fossa séptica + filtro } \\
\text { anaeróbio }\end{array}$ \\
\hline $25<\mathrm{C} \leq 80$ & De 501 a 1.000 & 80 & $\begin{array}{c}\text { Reator de manta de lodo }+ \\
\text { biofiltro aerado }\end{array}$ \\
\hline $\mathrm{C}>80$ & Acima de 1.500 & 85 & Lodos ativos \\
\hline
\end{tabular}

Fonte: DZ-215.R-4 (2007)

Segundo a DZ-215.R-4, estabelecimentos com número de funcionários variando entre 101 a 500, intervalo no qual se enquadrou o canteiro em estudo, deve-se adotar um dispositivo que apresente $65 \%$ de eficiência mínima exigida ao sistema de tratamento dos efluentes (salvo exigências suplementares). Apesar do que determina as normas existentes, optou-se, para o tratamento de esgoto, pela instalação de uma fossa séptica com capacidade de 22.000 litros que receberá o esgoto oriundo do canteiro de obras, não havendo filtro auxiliando para melhor tratamento do efluente. 
Os efluentes gerados pela cozinha serão direcionados para uma caixa de gordura, sendo posteriormente direcionados para a fossa séptica. A fossa séptica está interligada à rede de esgoto publica existente.

A fossa séptica adotada em forma retangular com 2,00 de largura, e 5,50 m de comprimento e 2,0 $\mathrm{m}$ de altura, com um poço de visitas de $0,8 \mathrm{~m}$ por $0,5 \mathrm{~m}$ de altura e tampões de fechamento hermético.

\section{CONSIDERAÇÕES FINAIS}

Conclui-se que de acordo com o decreto no 6.514, de julho de 2008, que dispõe sobre as inflações e sanções administrativas ao meio ambiente, estabelece o processo administrativo federal para apuração destas infrações, e dá outras providências a lei ambiental № 9.605, de novembro de 1998 que dispões sobre as sanções penais e administrativas derivadas de condutas a atividades lesivas ao meio ambiente é cabível multa, podendo variar de $\mathrm{R} \$ 50,00$ (cinquenta reais) a $\mathrm{R} \$$ $50.000 .000,00$ (cinquenta milhões de reais), suspensão parcial ou definitiva das atividades como punição pelo preposto ou detenção de 1 até 4 anos é cabível para o canteiro estudado.

\section{REFERÊNCIAS}

Associação Brasileira de Normas Técnicas, Projeto, construção e operação de sistemas de fossas sépticos - NBR 7229, Rio de Janeiro, 1993.

Associação Brasileira de Normas Técnicas, Tanques sépticos - Unidades de Tratamento complementar e disposição final dos efluentes líquidos - Projeto, construção e operação- NBR 13969, Rio de Janeiro, 1997.

AZEVEDO NETTO, J. M., Manual de Hidráulica, Ed. Edgard Blucher Ltda, 9ạ Edição, São Paulo, 2015.

BERNARDES, R.S. SOARES, Esgoto combinados e controle da população. Ed. Brasília, Caixa Econômica Federal, 2004.

BRASIL. DECRETO № 6.514, de 22 de julho de 2008, Dispõe sobre as infrações e sanções administrativas ao meio ambiente, estabelece processo administrativo federal de apuração destas infrações, e dá outras providências. Diário Oficial da União, Brasília, DF, 23 jul. 2008. Seção 1, p.01. Disponível em:<http://www.planalto.gov.br/ccivil_03/_ato2007-2010/2008/decreto/D6514.htm>. Acesso em 10/01/2020.

BRASIL. LEI № 9.605, de 12 de fevereiro de 1998, Dispõe sobre as sanções penais e administrativas derivadas de condutas e atividades lesivas ao meio ambiente, e dá outras providências, Diário Oficial da União, Brasília, DF, 13 fev. 1998. Seção 1, p. 25. Disponível em: <http://www.planalto.gov.br/ccivil_03/LEIS/L9605.htm>. Acesso em 10/01/2020. 
BRASIL. Norma Regulamentadora 18, de 08 de junho de 1978, Condições e Meio Ambiente de Trabalho na Indústria da Construção. Ministério do Trabalho e Emprego, Brasília, DF, 06 jul. 1978. Disponível em:< http://portal.mte.gov.br/images/Documentos/SST/NR/NR18/NR18.pdf >. Acesso em 10/03/2020.

BRASIL. Resolução 357, de 17 de março de 2005, Dispõe sobre a classificação dos corpos de água e diretrizes ambientais para o seu enquadramento, bem como estabelece as condições e padrões de lançamento de efluentes, e dá outras providências, Conselho Nacional do Meio Ambiente, Brasília, DF, 18 mar. 2005.2 Disponível em:< http://www.mma.gov.br/port/conama/legiabre.cfm?codlegi=459>. Acesso em 29/02/2020

NUVOLARI, ARIOVALDO, Esgoto Sanitário: Coleta, transporte, tratamento e reuso agrícola. Blucher. São Paulo 2011.

PACHECO J.E., VOLSCHAN I.J., Tratamentos de esgotos sanitários em empreendimentos habitacionais. Ed. Brasília: Caixa Econômica Federal, 2009.

RIO DE JANEIRO (Estado). DIRETRIZ DZ-215.R-4, de 25 de setembro de 2007, Diretriz de controle de carga orgânica biodegradável em efluentes líquidos de origem sanitária, de 25 de setembro de 2009. Diário Oficial do Estado do Rio de Janeiro, Rio de Janeiro, RJ, 08 nov. 2007. Disponível em: < http://www.inea.rj.gov.br/cs/groups/public/documents/document/zwew/mde0/ edisp/inea0014 063.pdf>. Acesso em 30/01/2020 